\title{
Contracampo
}

\section{Risco, sofrimento e vítima virtual: a política do medo nas narrativas jornalísticas contemporâneas}

\author{
Risk, suffering and virtual victim: \\ the politics of fear in contemporary journalistic narratives
}

Paulo Vaz

paulorgvaz@uol.com.br Professor PPGCOM/ECO/UFRJ

Janine Miranda Cardoso

janine@icict.fiocruz.br Professora PPGICS/Icict/Fiocruz

Carla Baiense Felix carlabaienses@yahoo.com.br Professora do Departamento de Comunicação Social da UFF

Ao citar este artigo, utilize a seguinte referência bibliográfica

VAZ Paulo, CARDOSO, Janine Miranda e FELIX, Carla Baiense. Risco, Sofrimento e Vítima Virtual: a Política do Medo nas Narrativas Jornalísticas Contemporâneas. In: Revista Contracampo, n‥ 25, dez de 2012. Niterói: Contracampo, 2012. Pags: 24-42.

Enviado em: 25 de set. de 2012)

Aceito em: 18 de dez. 2012

\section{PPGCOM U.m.}

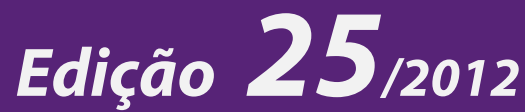

Ensaio temático "Mídia e Medo"
Contracampo

Niterói $(R J), n^{\circ} 25$, dez/2012. 


\section{Resumo}

O artigo examina aspectos discursivos e políticos do medo em sua singularidade histórica, a partir da exposição do sofrimento de estranhos no espaço público. A relação entre cultura e sofrimento privilegia quatro tópicos: i) a transformação do sofrimento em questão política na cultura ocidental; ii) a seleção dos estados e condições considerados para uma dada época histórica como sofrimentos relevantes e evitáveis através da ação política; iii) atribuição de responsabilidade pelo sofrimento de estranhos e, iv) o modo de endereçar a audiência. $A$ base empírica reúne matérias de jornais e telejornais sobre crimes, catástrofes e epidemias, produzidas a partir de 1980, e permite refletir sobre as repercussões éticas da política do medo contemporânea, conceituada como política da vítima virtual.

Palavras-chave: Risco; Medo; Jornalismo.

\section{Abstract}

The article examines the discursive and political aspects of fear by analyzing the historically situated exposure of the suffering of strangers in the public sphere. The analysis of the relations between culture and suffering privileges four topics: (1) the transformation of suffering into a political question in the West; ii) the repertoire of states and conditions each historical period discerns as socially relevant and avoidable through political action; iii) the attribution of responsibility for the suffering of strangers and iv) how the audience of suffering is addressed. Research draws on newspieces in the print media and on TV news on crime, catastrophes and epidemics, published from the 1980s onwards and allows for a reflection about the ethical repercussions of the contemporary culture of fear, here conceptualized as the politics of virtual victim.

Keywords: Risk, Fear, Journalism. 
$\mathrm{E}$

m 25 de Setembro de 2008, o comediante norte-americano Jon Stewart (2008), conhecido por usar o noticiário de jornais e TVs conservadores como matéria-prima, conseguiu tornar visível a estrutura formal da retórica política do risco. Na noite anterior, o então presidente George W. Bush tinha feito um pronunciamento à nação pedindo a aprovação imediata pelo Congresso do plano de ajuda aos bancos ameaçados de bancarrota. $\mathrm{O}$ comediante mostrou como esse discurso era formalmente idêntico ao pronunciamento do presidente, feito cinco anos antes, anunciando a intervenção militar no Iraque.

A identidade formal estava apoiada em três pontos. Primeiro, as ações a serem tomadas tinham problemas de legitimidade. Entrar em guerra significa propor o sacrifício de cidadãos. À diferença da ação militar contra o regime dos Talibãs no Afeganistão, que podia ser vista como reação de defesa contra os terroristas que atacaram o solo norte-americano em 11 de Setembro, a perda de vidas devido à invasão do Iraque tinha que se apoiar apenas na possibilidade de um ataque futuro. De forma similar, a defesa do plano de ajuda aos bancos fundava-se na ideia de um sacrifício necessário para evitar um risco futuro: os efeitos da crise no sistema financeiro sobre o cidadão comum. $\mathrm{O}$ esforço político para transformar a iniciativa em prioridade pública se torna ainda maior quando se admite que uma das causas da crise são as próprias práticas duvidosas das instituições financeiras. Além do imenso custo para os contribuintes - cerca de 700 bilhões de dólares - a medida ainda reforçava a crença, presente em diversos países, de que os ricos e poderosos nunca pagam pelos erros que cometem.

O segundo ponto em comum é a proposição de que os riscos aumentariam muito se uma ação não fosse feita imediatamente; no caso da guerra contra o Iraque, afirmava-se que o governo norte-americano não deveria conceder mais tempo aos inspetores nucleares da ONU porque a evidência irrefutável - o famoso "smoking gun" - poderia ser um novo ataque terrorista, agora com armas de destruição de massa. Da mesma forma, a demora na aprovação do plano de socorro aos bancos agravaria o risco de colapso do sistema bancário. 
O terceiro ponto é o esforço retórico de transformar o meramente possível em quase real por enunciar vividamente as consequências nefastas de nada fazer: não atacar Saddam Hussein traria para o horizonte dos norte-americanos ditadura, genocídio e morte de dezenas ou centenas de milhares; não dar dinheiro aos bancos significaria a possibilidade de perda da casa própria e desemprego para milhões.

O estabelecimento pelo comediante da semelhança entre o discurso da guerra e o discurso da crise indica imediatamente que uma análise das narrativas midiáticas do medo não precisa se limitar ao estudo do terrorismo e do seu primo doméstico, o crime, especialmente aquele ocorrido no espaço público e com seleção aleatória de vítima. $\mathrm{O}$ uso da retórica do risco na construção de um problema econômico como questão pública sugere que a produção do medo é um objetivo de discursos que tratam de vários temas; de fato, o medo será um elemento central em narrativas midiáticas sobre epidemias, catástrofes e acidentes. Como a narrativa do medo está presente em mais de um país, como nos mostra a articulação entre crime e medo no jornalismo brasileiro nas últimas duas décadas, podemos pensar que essa generalidade indica uma característica ética e política central nas culturas ocidentais contemporâneas: a tendência é apenas aceitar sacrifício no presente quando são construídas as consequências negativas associadas ao não-sacrifício.

A questão imediata é conceituar as narrativas de medo de modo a apreender porque são simultaneamente genéricas (porque usadas para diferentes temas) e singulares (porque seriam próprias das culturas ocidentais contemporâneas). As narrativas de medo são, tipicamente, construídas a partir da exposição do sofrimento de estranhos no espaço público. E essas narrativas têm a peculiaridade de promover a identificação, por aproximar da audiência a possibilidade de acontecer com ela o que aconteceu com o sofredor.

Para pensar as narrativas atuais de medo do crime em sua singularidade histórica, não privilegiamos como objeto as diferenças históricas nas narrativas de crime, sob a hipótese, por exemplo, de que antes tinham destaque os crimes passionais, cuja função não seria atemorizar, mas, sim, servir de válvula de escape para as inúmeras insatisfações domésticas da audiência, enquanto, hoje, o privilégio jornalístico recai sobre os crimes cometidos por estranho e ocorridos no espaço público. Nem tampouco o objeto de historicidade é o medo que, seguindo a narrativa de secularização, teria antes 
como causadores seres sobrenaturais e, posteriormente, outros seres humanos. Neste artigo, interessado na história do nexo entre discurso e política, a unidade de variação é a exposição do sofrimento de estranhos no espaço público.

A escolha dessa unidade torna central a relação entre cultura e sofrimento, com ao menos quatro lugares para analisar a mudança histórica. O primeiro estipula a diferença entre o período moderno e o pré-moderno na cultura ocidental: o sofrimento de estranhos é uma questão que cabe à Igreja ou à política? É distintiva da modernidade a transformação do sofrimento de estranhos em questão política, trazendo para a esfera pública o que antes cabia à religião ou estava limitado ao âmbito privado, a saber, o compromisso de agir para erradicar ou reduzir o alcance e a força do tipo de sofrimento exemplificado pelo sofredor. Antecipando um argumento crucial, se o espaço público moderno surgiu com a exposição do sofrimento de estranhos e a convocação para ação transformadora, a política do medo contemporânea pode ser pensada como uma transformação nessa tradição. E a mídia, em particular o jornalismo, por sua autoridade social para enunciar o verdadeiro, é um espaço privilegiado dessa operação ${ }^{1}$.

Após determinar a diferença entre religião e política, o segundo lugar é a seleção cultural dos inúmeros estados e condições suportadas pelos seres humanos e que podem ser tidos como de sofrimentos contingentes, isto é, sofrimentos que são relevantes para uma dada época histórica e evitáveis através da ação política (GUSFIELD, 1981).

O que determina a seleção de um sofrimento para entrada no espaço público não é sua intensidade, nem o número de sofredores; é, sim, sua capacidade de expressar a violação de valores básicos de uma cultura. Se um valor maior é a recusa de uma desigualdade social extrema entre os seres humanos, a fome ou a qualidade da moradia ou da educação serão destacadas; se o valor maior é a vida longa e prazerosa de indivíduos, todos os eventos que provocam morte abrupta ganharão relevância. Por outro lado, se o que vale é o bem-estar do indivíduo, perderão posição hegemônica no espaço público os sofrimentos que melhor expressam a desigualdade. A mudança histórica aparece então como um jogo de cena teatral: certos sofrimentos que antes eram

\footnotetext{
${ }^{1}$ Para produzir esses efeitos, o espetáculo tem que ser tomado como verdadeiro. Se experimentado como ficção, que associa medo e prazer, o espetáculo não leva a audiência a inquietar-se com o seu sofrimento e o do outro.
} 
iluminados passam para uma relativa obscuridade, enquanto outros são projetados para frente do palco.

Um terceiro lugar é a diferença no modo como as narrativas atribuem responsabilidade à audiência a partir da exposição do sofrimento de estranhos. $\mathrm{Na}$ identificação proposta, a mudança histórica pode ser observada na construção ou não de responsabilidade - direta ou indireta - da audiência pelo sofrimento exposto. Na política da piedade, a audiência é construída como os felizes, à diferença do sofredor, e responsável pelo sofrimento deste, nem que seja por nada fazer quando poderia.

Na política da vítima virtual ${ }^{2}$, a audiência é estimulada a se conceber na mesma condição daquele que sofre, o que desloca a busca da responsabilidade pelo sofrimento para um personagem outro. Associado tanto a esse nexo de responsabilidade, quanto ao tipo de sofrimento escolhido, aparece, por fim, um quarto lugar para observar a diferença histórica nas narrativas jornalísticas: o modo de narrar o sofrimento.

Para usar a memória de imagens que marcaram o jornalismo na década de 1970, temos o ventre inchado de crianças esqueléticas na África e a garota nua chorando desesperada e correndo para fugir de um bombardeio de Napalm. Para a produção da vítima, a memória ainda recente dos ataques do PCC na cidade de São Paulo, em 2006, serve de exemplo. No dia 15 de maio daquele ano, o Jornal Nacional da TV Globo acompanha um repórter que passa ao lado de um ônibus queimado. A narrativa nos convida a entrar no ônibus um pouco antes do ataque: "Os primeiros alvos foram os policiais, mas agora a intimidação chega ao cidadão comum. Quem passa por aqui e vê o esqueleto de um ônibus como este logo imagina que podia estar aí dentro" (MEDO..., 2006). E se o espectador morar em São Paulo ou em uma cidade que sofre com ações do crime "organizado", dificilmente suspirará de alívio ao pensar que é pouco provável que algo de semelhante lhe aconteça.

Em diversas pesquisas realizadas nos últimos dez anos e que tinham como objeto a mudança histórica nas narrativas jornalísticas de crimes, acidentes, catástrofes naturais e epidemias, identificamos, a partir dos anos 1980, uma mudança nos tipos de eventos noticiáveis e na estrutura narrativa acionada para construir causas públicas. No nível mais abstrato, a mudança é conceituada como passagem da piedade ao risco. Nas narrativas jornalísticas, essa passagem se concretiza pela emergência da vitima virtual

\footnotetext{
2 Política da vítima virtual é a conceituação que estamos propondo para a política do medo contemporânea.
} 
como figura subjetiva e política característica de nossa atualidade, bem como pelo predomínio de um novo ideal de justiça social: o direito à rotina segura e feliz. ${ }^{3}$

Neste artigo, apresentaremos, primeiro, o conceito de política da piedade, recorrendo às pesquisas já realizadas para mostrar como as narrativas jornalísticas a implementavam. Depois, analisaremos conceitualmente a política da vítima virtual, correlacionando sua construção às narrativas de sofrimento contemporâneas. Por fim, nos propomos a pensar sobre as repercussões desse tipo de responsabilização.

\section{A diferença histórica: a política da piedade}

Arendt (1965) localiza a emergência da política da piedade no contexto da Revolução Francesa, ancorada por dois fatores: a universalização da regra moral e a articulação entre sofrimento e política. A ideia de que todos os homens nascem iguais permitiu o reconhecimento do sofrimento de estranhos como algo injusto e repreensível. Mas diferente do período anterior, em que a solidariedade é tratada como uma questão religiosa, na modernidade o sofrimento passa a ser uma questão política, articulado a condições sociais. Ou seja, um certo arranjo político determina as condições que produzirão o sofrimento e, portanto, uma ação política é capaz de reduzi-lo ou eliminálo.

De modo geral, a narrativa da política da piedade articula os fatos a uma determinada estrutura social e política, cuja consequência perversa é o sofrimento. Por outro lado, a narrativa despersonaliza o sofredor, transformado em representante de uma situação que afeta a todo um grupo. Aquele que está diante do sofredor não pode ajudar local e imediatamente, na medida em que ser solidário significa a ação mediada de transformar a sociedade.

Assim, nessas narrativas, a audiência é endereçada como os felizes que devem agir politicamente para reduzir os sofrimentos dos infelizes (BOLTANSKI, 1999). Se deve agir, a audiência também é endereçada como responsável. A responsabilidade pode ser passiva, por mera omissão, quando se postula que fazer algo reduz o sofrimento e, assim, que nada fazer amplia as agruras do sofredor.

\footnotetext{
${ }^{3}$ Para maior detalhamento da base empírica e conceitual aqui sintetizada, consultar Vaz e colaboradores (2005, 2006, 2009, 2011), Felix (2012), Cardoso (2012).
} 
Mas a forma principal de conceber a responsabilidade da audiência, que marcou a política nos séculos XIX e XX em diversos países ocidentais, foi a responsabilidade ativa. A partir de uma teoria da exploração, supõe-se que a felicidade de alguns resulta da infelicidade de muitos. A audiência se beneficiaria da estrutura social que causa sofrimentos e, portanto, está em dívida em relação a todos os que são apresentados a ela como sofredores. Estes, por excelência, são os trabalhadores; cabe notar que não eram denominados vítimas, mas, sim, miseráveis, pobres, explorados, oprimidos.

Embora concorressem com outros parâmetros, os critérios de seleção e as formas de narrar o sofrimento de estranhos predominantes na mídia brasileira dos anos 1980 eram tributários dessa tradição. Nas telas e páginas de jornais, aqueles provocados por crimes, desastres naturais, seca e epidemias eram os mais relevantes. Todos, ou a maior parte, tendendo a serem relacionados às desigualdades estruturais e reservando às elites o papel político de resgatar a dívida social exacerbada pela ditadura militar (REIS, 2005).

Em dezembro de 1981, o estado do Rio foi atingido por uma tromba d'água, com 44 mortes, concentradas entre os moradores de encostas da cidade de Petrópolis. A reportagem de uma revista jornalística de assuntos gerais explica a concentração. "Os temporais, como os impostos, caem para todos. Mas a proteção do Estado e as catástrofes naturais não. A primeira costuma ser despejada onde há riqueza. As calamidades desabam sobre os mais pobres." Na sequência, ficamos sabendo que o governador Chagas Freitas teria comemorado com seus assessores o fato de "nada" ter acontecido; é que a Zona Sul não tinha sido afetada pelas chuvas ( $O$ Rio quase afogado nas chuvas. Veja, 09 de dezembro de 1981, p. 20-23).

A reportagem Balão arruína vida de uma família, publicada pelo jornal $O$ Globo, em 26 de junho de 1984 (chamada primeira página), mantém a conexão com as injustiças sociais. Com foto e chamada de capa, a matéria conta a história de uma família, moradora de Vila Maria, que perdeu a casa depois da queda de um balão. O texto vai além da narrativa do fato em si e retrata a vida difícil do casal, cujo marido está desempregado, relacionando a situação na favela à dificuldade por que passa todo o país, incapaz de prover as condições básicas de sobrevivência à população mais pobre. O título da reportagem na página interna torna esta conexão ainda mais clara: "Balão fez 
mais difícil vida de marceneiro desempregado", enquanto o texto relata: “[...] Carlos Alberto saiu cedo de casa ontem a fim de ganhar o mínimo necessário à compra de alimentos para seus filhos. Tímida e constrangida, Georgina pediu para o marido e os filhos "um emprego"” (Balão fez mais difícil vida de marceneiro desempregado. $\boldsymbol{O}$ Globo, Idem, p. 11).

Se a reportagem fosse produzida hoje, a ênfase estaria sobre a imoralidade daqueles que expõem outros a riscos. E mais, o fato de a vítima estar numa situação econômica crítica, não teria relevância, já que o importante é a relação entre a inconsequência de alguns e a generalidade do risco.

Mas é na exposição dos sofrimentos nas reportagens de crime que fica mais clara a narrativa típica da política da piedade. Sintomática deste período é a matéria do mesmo jornal sobre a visita de Dom Eugênio Sales, arcebispo da Arquidiocese do Rio de Janeiro, ao presídio Evaristo de Moraes. Em 11/07/1984, “Cardeal pede solução para presos com penas cumpridas" narra o sofrimento de detentos, vítimas da morosidade do sistema penitenciário. Mais uma vez, conclama-se a uma ação política capaz de suspender o sofrimento das vítimas. Nas palavras de Dom Eugênio "Esses atrasos provocam um clima de revolta muito grande, e são uma injustiça contra o preso [...] Não acuso ninguém, sei que os juízes estão sobrecarregados, mas a estrutura deveria ser alterada" (Cardeal pede solução para presos com penas cumpridas. $O$ Globo, 11 de julho de 1984, p. 6).

A crença numa comum humanidade e na possibilidade de "curar" os criminosos independia da violência do ato. Em setembro de 1983, O Globo noticiava que membros da então Falange Vermelha assassinaram oito detentos ligados à Falange Jacaré no presídio da Ilha Grande; um deles morto com quatrocentas facadas. No dia seguinte, editorial de primeira página explica que motins, fugas em massa e a guerra entre facções criminosas nas prisões resultam do "estado de ruína do nosso sistema carcerário" e defende a resolução do problema com base na recuperação dos bandidos: "Ao homem de bem não escapa a dimensão do ser humano, mesmo na pele de um monstro. E por formação e racionalidade ele quer as penitenciárias funcionando realmente como instituições de ressocialização do criminoso e não como depósito e arena de bandidos irrecuperáveis" ( $O$ Globo, 1983, p.1, Editorial). 
Os fragmentos apresentados e seus insuspeitos enunciadores deixam claro que a perspectiva predominante não pode ser reduzida a uma determinada posição ideológica, mas expressam os valores característicos de uma cultura que por almejar os ideais de igualdade e liberdade se inquieta com as desigualdades sociais que afligem os seres humanos.

A desresponsabilização dos indivíduos pelos crimes que praticavam e sofrimentos que causavam é outra característica da cultura moderna e postulava, simultaneamente, a provisoriedade da separação entre "nós"/“eles" e a erradicação futura de grande parte dos sofrimentos. Sua presença é vívida nos dois modos então hegemônicos de pensar a causalidade para o crime. Na explicação por anomia, os crimes acontecem porque as oportunidades ilegais de ascensão social prevalecem sobre as legais (GARLAND, 2001). Aqui, o criminoso era uma vítima e a transformação da sociedade necessária para eliminar o sofrimento das vítimas. Também a explicação pela anormalidade desresponsabiliza o criminoso ao vê-lo como um doente a ser curado (FOUCAULT, 1996). Em ambas, a audiência é instada a ajudar os criminosos, sofredores e vítimas do sistema.

Tais características se expressam de forma clara na proposta de identificação com o criminoso. De fato, chama atenção que o ponto de vista do agressor seja o fio condutor das narrativas, tanto no interesse em contextualizar sua história de vida quanto no espaço concedido para que ele mesmo apresente suas motivações. Uma reportagem de 1983, Demitido, motorista mata a tiros Gerente da firma, é exemplar. A matéria encarrega-se de mostrar seu desespero com a perda do emprego, modo de aproximar a audiência do que seria estar naquela situação. Para o leitor atual, causa surpresa não só a defesa de um assassino, mas a ausência de informações sobre a vítima: nada sabemos de sua vida, não há justificativa para suas ações e nenhum parente lamenta sua morte (Ver O Globo, 21 de fevereiro de1983, p. 17).

O lastro cultural desse trabalho de sentido é percebido na extensão da mesma estrutura narrativa para outros tipos de sofrimento, como se percebe nas várias matérias sobre a seca que assolava a vida dos nordestinos, veiculadas em $1983^{4}$, e na reportagem sobre a endemia de enterite que causava "anualmente mais de 23 mil mortes de crianças em Pernambuco", em 1984, todas do Jornal Nacional. Nesta última, a crítica social

\footnotetext{
${ }^{4}$ Foram analisadas para este artigo três reportagens, exibidas nos dias 18 de junho, 30 de julho e 08 de agosto, disponíveis em http://memoriaglobo.globo.com. Acesso em 25 de setembro de 2012.
} 
mira claramente uma causa agregadora para explicar o evento: os elevados índices de mortalidade e desnutrição infantis são associados, logo no início da matéria, à falta de saneamento básico. Mais adiante, com imagens de uma favela de Recife, o off afirma que "convivendo o dia inteiro com a fome e a lama, as crianças enfrentam nessa época de inverno o seu maior inimigo, a enterite". Na cadeia de determinação da doença, o vírus é apresentado como uma condição a partir da qual a 'verdadeira' causa, a pobreza, produz seus efeitos, a morte de crianças. Por essa forma de causalidade, os políticos são questionados se nada fazem para modificar as condições sociais que causam o sofrimento. Não é casual que a reportagem termine com a repórter insistentemente perguntando ao ministro da saúde se era normal a morte de tantas crianças e se não havia nada que o ministério pudesse fazer (Ver $A$ enterite ameaça as crianças do nordeste. Jornal Nacional, 23 de maio de 1984).

Nas matérias sobre crime, pontuamos o quanto a narrativa convida à identificação com o agressor e silencia sobre as vítimas. Nas matérias sobre doenças coletivas e catástrofe, outra estratégia retórica tece o vínculo da audiência com os sofredores: o anonimato e o privilégio das do corpo sofredor. Mais do que uma função referencial, essas imagens expressam de modo marcante o posicionamento diferencial da audiência. Na reportagem sobre a enterite, vemos crianças descalças e quase desnudas enquanto a repórter denunciava a desnutrição e a falta de saneamento na favela. A mesma repórter já entrara numa casa para entrevistar uma mãe que segurava a filha, vítima da doença; a câmera se detém no corpo esquálido e na face amarelada da criança. A mãe ainda afirma, em evidente contradição com a imagem, que sua filha não estava tão mal e que "tem dia que ela tá obrando direitinho". A distância entre felizes e infelizes, incontornável na exposição do corpo da criança, é composta pela dimensão de alienação: o sofredor sequer reconhece que sofre.

Tais fragmentos discursivos expressam uma sensibilidade social na qual ainda era proeminente a forma como a modernidade concebeu os sofrimentos humanos como evitáveis, vinculando-os à historicidade dos problemas coletivos e das respostas que encontravam.

\section{Política do medo e vítima virtual}


A partir dos anos 1990, e mais marcadamente nos 2000, é perceptível a mudança nos tipos de sofrimento noticiados, nas causas que os explicam e nas formas de narrá-los. ${ }^{5} \mathrm{O}$ deslocamento que responde pela singularidade dessas narrativas pode ser apreendido na substituição do que permanece invariável: não mais eventos vinculados à estrutura social, mas acontecimentos que ocorrem no espaço público com seleção aleatória de vítimas: crimes, catástrofes naturais, epidemias e acidentes.

Retoricamente, a mudança materializa-se em três operações que estruturam as diferentes notícias e resultam da aplicação contrafactual da lógica do risco: o evento poderia acontecer com qualquer indivíduo, pode ocorrer novamente e poderia ter sido evitado. Se o conceito de perigo indica um evento futuro que pode ou não acontecer, o conceito de risco dele se diferencia ao supor a dupla contingência do evento negativo (LUHMANN, 1993, p. 16). Além de ser meramente possível como um perigo, seu advento depende, ao menos em parte, de uma decisão tomada no presente, que pode ou não ser feita. Risco não é apenas oposto ao acaso, por implicar um cálculo probabilístico do futuro; é também oposto ao fatalismo: o evento previsível pode ser evitado pelas ações humanas.

A exemplo do esquema apresentado na introdução, tais eventos se prestam facilmente à generalização do sentimento de vulnerabilidade, da urgência de intervenções preventivas e estabelecem, por retrospectiva ou antecipação, a responsabilidade individual por sua ocorrência. Dito de outra forma: se aplicada a um evento que já ocorreu, a lógica do risco recua a um momento do passado onde teria havido a capacidade de prevê-lo e evitá-lo. A narrativa do Jornal Nacional sobre a última grande epidemia de dengue, também no Rio de Janeiro, expressa esse movimento temporal, como o editorial de 24 de março exibe de forma cristalina:

A dengue não era novidade para ninguém. Pelo menos não deveria ser. Mas, apesar de tudo isso, neste ano de 2008, milhões de brasileiros estão assustados porque milhares ficaram doentes $\mathrm{e}$

\footnotetext{
${ }^{5}$ A crise da política da piedade está associada à passagem do capitalismo de produção para o de consumo, ao desenvolvimento tecnológico e a uma série de eventos intensificados na segunda metade do século passado. Sua caracterização extrapola os limites deste artigo, mas destacam-se a valorização do testemunho de sobreviventes do holocausto em detrimento das provas, a emergência de movimentos por direitos civis e, mais recentemente, a mobilização de vítimas de crime e de acidentes. Todos podem ser apontados como decisivos na trajetória de autonomização e valorização da posição de vítima, e constitutivos das práticas de poder contemporâneas. Cf. Vaz e Rony (2011) e Vaz (2009).
} 
morreram dezenas. E, desta vez, no Rio de Janeiro (Willian Bonner, Editorial Jornal Nacional, 24 de março de 2008).

Se, ao contrário, trata-se de evitar algo virtualmente possível, todos os esforços para impedir sua ocorrência são justificados no presente. Daí a ênfase jornalística em matérias que discutem o recrudescimento das leis para coibir a corrupção policial ou para os motoristas que ingerem bebida alcoólica, em reportagens que atribuem a construção de casas em áreas de risco ao populismo político e na insegurança dos aeroportos associada à negligencia do poder público.

Para insistir na possibilidade de prevenção de riscos, e, por isto mesmo, na negligência dos agentes públicos, vale a pena recordar a reportagem de Veja a respeito da catástrofe ocorrida em Angra dos Reis, no Rio de Janeiro, no Réveillon de 2010.

Tudo era previsível. Na bela região em torno da Baía de Angra, com suas 365 ilhas e mais de 2000 praias, chove quase o dobro da média do Rio de Janeiro, e a instabilidade das encostas é conhecida [...] Apesar disso, nunca foi feito um mapa geológico para verificar quais terrenos são impróprios para construção. A ocupação do solo é regida por regras municipais, estaduais e federais que se sobrepõem e ninguém as cumpre. Como se não bastasse, existe um impressionante histórico de corrupção nos órgãos responsáveis pela fiscalização em Angra (Trágico, absurdo, previsível. Veja, 09 de Janeiro de 2010. p. 56).

Nesse tipo de causalidade, a tendência a despersonalizar os sofredores cede lugar ao interesse pela singularidade de suas histórias, realçando o quanto eram felizes até então. A individualização, no entanto, é uma forma de generalização. Na cobertura da epidemia de dengue em 2008, além da nomeação de cada vítima, os relatos de agravamento da doença e morte foram insistentemente intercalados com características e preferências pessoais, como o time de futebol, o animal de estimação, as novelas e, principalmente, os sonhos para o futuro. A felicidade até então existente e brutalmente interrompida é claramente marcada pelo uso abundante de fotos privadas das vítimas alegres, fantasiadas, brincando e com uniforme escolar. A rotina segura e prazerosa é a condição para os planos de futuro: Samuel queria ser bombeiro ou médico para salvar 
vidas; Amanda economizava para sua festa de 15 anos; Patrick ansiava pelo começo das aulas (Ver Crianças que morreram de Dengue. Jornal Nacional, 25 de março de 2008).

Por que informações tão íntimas aparecem na narrativa, quando para o entendimento do acontecimento seriam irrelevantes? Parece claro que elas se destinam a realçar a inocência das vítimas, aumentar a indignação, favorecer a identificação da audiência com os sofredores e reforçar a aliança com o telejornal que denuncia tamanho escândalo. Trabalho de sentido que é complementado pela dor incomensurável dos pais: seus relatos exemplificam uma diferença significativa na forma de expor o sofrimento que pode ser sintetizada como a passagem do Crucificado à Pietá (FASSIN, 2010). Se no primeiro tipo, como vimos, as marcas visíveis do corpo que sofre estabelecem imediatamente a distância com a audiência, no segundo, as imagens e os testemunhos de parentes sobre a imensidão da perda, ao contrário, favorecem a identificação direta: qualquer um é capaz de experimentar angústia e revolta ao imaginar-se diante da perda de um ente tão querido.

Para a comparação histórica com a técnica anterior de expor o sofrimento, note-se que todas as vítimas de dengue que apareceram no Jornal Nacional em 25 de março de 2008 eram pobres e moravam em Bangu, Cidade de Deus, São João de Meriti, zona rural de Campos, Itaboraí, Duque de Caxias, Realengo. A pobreza, contudo, já não era a característica que favorecia a identificação, na forma de a audiência pensar como seria estar naquela condição. Como qualquer um, independente de suas vicissitudes, as vítimas já seriam felizes em suas vidas privadas; o que suscita a compaixão é a perda dessa felicidade. Assim, a pobreza pode ser mostrada e mesmo nomeada, mas, na comparação histórica, é duplamente elidida: não é obstáculo à felicidade, não aponta para desigualdades sociais, nem é articulada causalmente à emergência da doença e do sofrimento.

Nas notícias sobre crime, o destaque passa a ser dado às matérias que caracterizam a cidade em termos de áreas de risco: sequestros-relâmpago, balasperdidas, trocas de tiros entre policiais e bandidos ou entre traficantes de facções rivais. A cada novo incidente, a audiência, já habituada com esse tipo de notícia, será capaz de recordar casos semelhantes, mesmo sem a ajuda do jornal. No mais das vezes, porém, os meios de comunicação facilitam o trabalho da audiência: associam o acontecimento a casos semelhantes ocorridos anteriormente ou fornecem algum dado estatístico, 
apresentando, assim, o incidente como uma incidência. Frequentemente, o lead da reportagem era "mais uma vítima da violência na cidade".

Uma segunda estratégia retórica não generaliza o crime, mas constrói uma certa imagem do agressor, cada vez mais distanciada da anterior que descrevia suas ações como condicionadas pelo contexto social. Na atualidade, ao contrário, quase sempre são referidos como agentes genéricos - bandidos, criminosos, traficantes - e seus atos, ao invés de terem justificativas, são marcados por um desrespeito pela vida humana que os torna ainda mais incompreensíveis e condenáveis. Em outras palavras, essa forma de atribuir responsabilidade constitui uma 'comunidade imaginada' de vítimas virtuais que é necessariamente excludente, por traçar o diferente do 'nós' como monstruoso, e assim justificar políticas conservadoras e autoritárias.

Há mais um modo de o 'nós' das vítimas virtuais ser excludente, agora no sentido da escolha das vítimas concretas que representam o cidadão e merecem nossa atenção: a tendência é privilegiar os indivíduos de classe média que estavam em sua rotina. Tomemos como exemplo a reportagem Tiroteio entre PMs e traficantes pára a Av. Brasil durante a madrugada, publicada em $O$ Globo em 29 de abril de 2001 (p. 22). O sofrimento que aparece no primeiro parágrafo é o dos motoristas apavorados que abandonavam seus carros e fugiam correndo ou davam ré e voltavam pela contramão. Questionar concretamente a exclusão do sofrimento dos moradores de favelas situadas ao longo da Avenida Brasil já reduziria a desumanidade dos criminosos, pois articularia a criminalidade ao contexto social. Ao mesmo tempo, evitaria a tendência do senso comum de identificar os moradores de favela com criminosos.

Esta relativa obscuridade do sofrimento dos moradores de favela aparece nas narrativas através do predomínio da polícia e dos moradores de classe média como fontes e testemunhas. Na reportagem Rotinas se alteram pelo medo da Linha Amarela, publicada no jornal $O$ Globo, em 2004, quem tem direito a narrar seu sofrimento é um médico, morador da Barra da Tijuca, obrigado a cruzar a Linha Amarela para chegar ao trabalho. Depois de ser vítima de uma série de incidentes na via expressa, tomou uma atitude radical: mudou-se para a Zona Sul. Na continuação, vê-se não mais o sofrimento de uma vítima real, mas de uma vítima virtual, representada por uma enfermeira da mesma equipe que, "obrigada" a cruzar a Linha Amarela, ilustra de forma contundente o cálculo de risco contemporâneo: “[...] O medo de levar uma bala perdida é maior do 
que o de sofrer um acidente de carro por estar em alta velocidade." ( $O$ Globo, 02 de Jan. de 2004, p.15).

\section{Vitimização e políticas conservadoras}

Embora tenhamos acentuado que outros tipos de evento podem ser usados pela política da vítima virtual, é fato que o crime mantém sua centralidade para as políticas do medo e para a discussão acadêmica. Paul Chevigny (2003), por exemplo, em estudo sobre o que considera a vitória do "populismo do medo" em eleições para cargos públicos em Nova Iorque, Buenos Aires, Cidade do México e São Paulo, concluiu que os candidatos conservadores têm mais chance de êxito quanto mais difíceis forem as condições sociais e econômicas da população e a incapacidade do Estado em reverter o quadro. Nestas circunstâncias, as pessoas têm medo de perder seus empregos, de que a economia sofra um abalo ou de que alguma calamidade ocorra. No caso do medo do crime, em especial, a resposta conservadora têm sido a de aderir a campanhas pautadas por este tipo de populismo, que prega no lugar do "Estado de bem-estar" o "Estado seguro", defendendo uma série de medidas tão discriminatórias quanto inócuas no combate à criminalidade.

O “populismo do medo" não afeta só eleições. A polícia de São Paulo entre o final dos anos 1980 e início dos 1990 matou mais cidadãos do que durante a ditadura. Enquanto as mortes de suspeitos e presos políticos ocorriam secretamente, os civis mortos por governos legitimamente constituídos ocorreram com o suporte legal do poder público. Segundo o pesquisador, "as políticas anticrime servem tanto para o controle social daqueles que são marginais, quanto para o controle social do resto de nós." 6

O que Chevigny chamou de "populismo do medo" - e deixa patente que sua hegemonia não é apanágio do Brasil ou da cidade do Rio de Janeiro -, nós conceituamos como política da vítima virtual. E para estimar o modo como um dado sofrimento é transformado em causa pública, analisamos a explicação de suas causas e responsabilidades, a construção dos personagens e a incidência do foco narrativo, em conexão com o lugar que a audiência é convidada a ocupar. O deslocamento da ênfase

\footnotetext{
${ }^{6}$ No original, "The point for me is not that the politics of anti-crime serves for social control of those who are marginal, but that it serves for the social control of the rest of us" (CHEVIGNY, 2003, p. 80-81).
} 
sobre o criminoso - produtor de violência, mas, sobretudo produto da desigual estrutura social - para o sofrimento das vítimas constitui, simultaneamente, a imagem desumana de todo aquele que nos põe em risco. É clara a resposta política suscitada: embora coletiva, é excludente, na medida em que circunscreve numa comunidade de vítimas virtuais aqueles que merecem ser protegidos.

$\mathrm{O}$ argumento deste artigo pode ser confundido com um elogio à forma moderna, fazendo parecer que esquecemos a brutalidade das biopolíticas sustentadas nos conceitos de norma e progresso e legitimadas pela defesa do direito à vida. Ao realçar a brusca transformação de valores que respondem pela singularidade do presente, no entanto, mantemos a oposição ao movimento retrógrado do verdadeiro: a cada vez que mudamos de crenças, nos pensamos instalados no pleno da verdade e, portanto, que o passado é idêntico ao presente. O contraste com o passado ainda recente permite, uma vez mais, analisar o modo como construímos a alteridade e questionar a ética que sustenta a relação que estabelecemos com nossos sofrimentos.

No Rio de Janeiro, há uma clara relação entre o aumento do número de matérias sobre crime, sobretudo nos anos 2000, e o registro de índices alarmantes de mortes por "autos de resistência". A tolerância em relação à morte de indivíduos por policiais e à aceitação da superpopulação das prisões é um dos modos como nossa sociedade autoriza a violência do Estado. Toda vez que nos percebemos em risco que não escolhemos correr, atribuídos a um outro monstruoso, parece não haver problema ético em aceitar a violência contra ele. E exigimos a garantia do 'sagrado direito' de decidir os sacrifícios que estamos dispostos a fazer para manter, por muito tempo, uma rotina segura e feliz. Na simplificação moral própria da vítima virtual, o que desaparece é a possibilidade de discussão coletiva sobre que sociedade queremos construir.

\section{Referências bibliográficas}

ARENDT, H. On Revolution. Londres: Penguin Books. 1965

BOLTANSKI, L. Distant Suffering: morality, media and politics. Cambridge: Cambridge University Press, 1999.

CARDOSO, J. M. Entre vítimas e cidadãos: risco, sofrimento e política nas narrativas do Jornal Nacional sobre as epidemias de dengue (1986-2008). Tese (Doutorado em Comunicação e Cultura), Escola de Comunicação, Universidade Federal do Rio de Janeiro, 2012. 
CHEVIGNY, P. The populism of fear - politics of crime in the Americas. Punishment \& Society, vol. 5, n. 1, p. 77-96, 2003.

FASSIN, D. La Raison Humanitaire. Paris: Seuil/Gallimard, 2010.

FELIX, C. B. Territórios proibidos: a construção da favela no noticiário e seus efeitos sociais. Tese (Doutorado em Comunicação e Cultura), Escola de Comunicação, Universidade Federal do Rio de Janeiro, 2012.

FOUCAULT, M. Vigiar e punir: nascimento da prisão. Petrópolis/RJ: Vozes, 1996.

GARLAND, D. The culture of control: crime and social order in contemporary society. Chicago: University of Chicago Press, 2001.

GUSFIELD, J. R. The culture of public problems. Chicago: University of Chicago Press, 1981.

LUHMANN, N. Risk: a sociological theory. New York: Aldine de Gruyter, 1993.

REIS, E. Perceptions of poverty and inequality among Brazilian Elites. In: REIS, E; MOORE, M. (Org.). Elite perceptions of poverty and inequality. New York: Zed Books, 2005, p. 2656.

STEWART, J. The Daily Show with Jon Stewart. Disponível em: http://www.thedailyshow.com/watch/thu-september-25-2008/clusterf--k-to-the-poor-house--dive-of-death. Acesso em 19 set. 2012.

VAZ, P; RONY, G. Políticas do sofrimento e as narrativas midiáticas de catástrofes naturais. Revista Famecos, v. 18, p. 218-234, 2011.

A mídia, a rotina e a vítima virtual In: BOCAYUVA, H.; NUNES, A. N. (Orgs.). Juventudes, subjetivações e violências. Rio de Janeiro: Contracapa, 2009, p. 129-146. VAZ, P.; CARVALHO, C. S.; POMBO, M. F. A vítima virtual e sua alteridade: a imagem do criminoso no noticiário de crime. Revista Famecos, v. 30, p. 71-80, 2006.

VAZ, P.; CARVAlHO, C. S.; POMBO, M. F.; JULIÃO, L. Pobreza e risco: a imagem da favela no noticiário do crime. Revista Fronteira, São Leopoldo, v. 7, n.2, p. 95-103, 2005.

\section{Fontes Primárias}

\section{O Globo -}

Ano 1983 - edições de 21 de fevereiro e 12 de setembro.

Ano 1984 - edições de 26 de junho e 11 de julho.

Ano 2001 - edição de 29 de abril.

Ano 2004- edição de 02 de janeiro.

Veja-

Ano 1981 - edição de 09 de dezembro.

Ano 2010 - edição de 09 de janeiro. 


\section{Jornal Nacional}

Ano 1983 - edições de1 8 junho, 30 julho e 08 de agosto.

Ano 1984 - edição de 23 de maio.

Ano 2006 - edição de 15 de maio.

Ano 2008 - edição de 24 e 25 de março. 